Abstracta Iranica Abstracta Iranica

Revue bibliographique pour le domaine irano-aryen

Volume 24 | 2003

Comptes rendus des publications de 2001

\title{
Album prefaces and other documents on the history of calligraphers and painters. Leiden, Brill, 2001, 103 p.
}

Vlad Atanasiu

\section{OpenEdition}

9 Journals

Édition électronique

URL : http://journals.openedition.org/abstractairanica/34464

DOI : 10.4000/abstractairanica.34464

ISSN : 1961-960X

\section{Éditeur :}

CNRS (UMR 7528 Mondes iraniens et indiens), Éditions de l'IFRI

\section{Édition imprimée}

Date de publication : 15 mai 2003

ISSN : 0240-8910

\section{Référence électronique}

Vlad Atanasiu, «Album prefaces and other documents on the history of calligraphers and painters. Leiden, Brill, 2001, 103 p. », Abstracta Iranica [En ligne], Volume 24 | 2003, document 148, mis en ligne le 05 janvier 2010, consulté le 25 septembre 2020. URL : http://journals.openedition.org/abstractairanica/ 34464 ; DOI : https://doi.org/10.4000/abstractairanica.34464

Ce document a été généré automatiquement le 25 septembre 2020.

Tous droits réservés 


\title{
Album prefaces and other documents on the history of calligraphers and painters. Leiden, Brill, 2001, 103 p.
}

\author{
Vlad Atanasiu
}

1 Treize textes en persan accompagnés de leur traduction en anglais sont présentés dans cet ouvrage. Ils se réfèrent aux artistes des cours princières de la Perse des Timūrides et des Safavides, auxquels s'ajoutent deux rapports d'ambassade et une généalogie de la maison de Timūr par un de ses descendants. Ce recueil s'adresse autant aux historiens de l'art intéressés par les sources écrites sur l'art et les artistes, qu'aux historiens de la Perse et de ses relations extérieures avec la Chine et l'Inde.

2 Son intérêt réside entre autres dans le fait que les textes qu'il publie sont passés jusqu'ici inaperçus: insérés dans des albums d'exemples d'écriture et de miniature, parfois répartis sous plusieurs cotes et souvent d'un accès peu aisé; la majorité appartiennent à des collections d'Istanbul.

3 Les onze préfaces d'albums sont caractérisées par l'aspect stéréotypé du style (métaphorique, avec peu de variation) et du contenu (apologie des commanditaires des albums et esquisse généalogique de la calligraphie et de la peinture). Dans un volume parallèle publié dans la même série chez Brill, Prefacing the Image, D. Roxburgh étudie la problématique posée par ce genre d'écrit (cf. c.r. $n^{\circ} 147$ ).

4 On voit apparaître l'activité des artistes à travers un rapport venant, semble-t-il, de la fondation artistique du prince Bāysunqūr, et qui consigne, pour chacun des artistes, l'état d'avancement des travaux qui lui ont été confiés (ex: 'Le jour de ce rapport Mawlānā 'Alî a commencé le dessin d'une enluminure-frontispice pour le Shāhnāme. Les yeux lui ont piqué quelques jours.').

5 Une collection de huit pétitions et décrets donne des informations brutes sur la vie quotidienne : demande d'un artiste à un patron pour lui acheter la maison où il vit ; demande d'un nouvel encrier pour remplacer l'encrier chinois, qui vient de se casser; estimation de la quantité de texte qui peut être écrite par jour ; ordre pour extraire des 
pierres semi-précieuses dans la région de Yazd; histoire terrifiante d'un manuscrit dont la réalisation a coûté la vie à plusieurs grands artistes sur près de cent ans.

6 Si les textes précédents varient en longueur d'un paragraphe à quelques pages, les rapports de mission (abrégés eux aussi ?) sont plus longs et abondent en observations ethnographiques, géographiques, en impressions personnelles aussi ; ils réservent par ailleurs une place copieuse à la description des banquets offerts aux émissaires et autres attentions dont ils ont fait l'objet.

7 Album prefaces... est une heureuse contribution à la connaissance de milieux artistiques persans par le biais du discours écrit qui les entourait, tantôt idéalisant ou formel, tantôt factuel (à signaler une autre publication similaire : H. R. Qīličçānī, Resālāt-ī dar Hošnevis̄ì va honar-hā-ye vābaste, Tehrān, Rowzane, 1373, 463 p.). W. Thackston luimême, professeur de persan et d'arabe à l'Université de Harvard, a une longue expérience dans le domaine de la traduction (Bābūr-nāma, sources sur l'histoire et l'art timūride, histoires populaires du Luristan...).

8 Le traitement des données est méticuleux (références aux spécimens conservés pour tous les artistes cités) et exhaustif malgré l'étendue des sujets couverts et des langues à interpréter (chinois, mongol et sanskrit sont rendus aussi bien en translittération qu'en original).

On regrette que la qualité de l'impression (résolution autour de 300 dpi, début de lignes parfois coupées dans le texte persan), le choix du papier (blancheur un peu agressive pour un papier qui se gondole facilement) et la mise en page (paragraphes orphelins, justification abusive par kašĩda-s) ne soit pas comparable aux premières publications du $\mathrm{XVII}^{\mathrm{e}}$ s. de la même maison Brill.

10 S'agissant d'un ouvrage de référence pourvu d'un apparat critique important, autrement dit d'un bel exemple d'hyperlien, la publication parallèle sur le Web de cet outil de travail scientifique serait sûrement opportune et ferait gagner bien du temps aux chercheurs qui travaillent la nuit lorsque les bibliothèques sont fermées (et qui n'ont pas les moyens de s'acheter l'ouvrage).

INDEX

Thèmes : 5.1. Monde iranophone

\section{AUTEURS}

VLAD ATANASIU

Paris 